\title{
Influence of changes in pancreatic tissue morphology and capillary blood flow on antibiotic tissue concentrations in the pancreas during the progression of acute pancreatitis
}

\author{
Th Foitzik, H G Hotz, M Kinzig, F Sörgel, H J Buhr
}

\begin{abstract}
Background-The ability of an antibiotic to reach bactericidal concentrations in tissue depends on numerous factors including tissue composition and regional perfusion. Although necrotising pancreatitis is characterised by progression of pancreatic necrosis over at least 96 hours and microcirculatory alterations, the impact of these changes on the concentration of antibiotics in the pancreas has not yet been investigated.
\end{abstract}

Aim-To determine and compare pancreatic tissue concentrations of imipenem and cefotaxime at different stages of acute necrotising pancreatitis in an animal model that has been shown to mimic closely the pathomorphological and bacteriological features of severe human pancreatitis.

Method-Acute necrotising pancreatitis was induced in rats by a standardised intraductal infusion of glycodeoxycholic acid and intravenous cerulein. Six hours $(n=16)$ and 48 hours $(n=16)$ after induction of pancreatitis, the animals were randomised for intravenous therapy with either imipenem or cefotaxime. Fifteen minutes after injection of the antibiotic, the animals were killed. Blood and the head of the pancreas were collected for determining imipenem or cefotaxime in serum and tissue; the splenic portion of the pancreas was prepared for histological examination. In an additional set of identically treated animals, pancreatic capillary blood flow (PCBF) was assessed by intravital microscopy before induction of acute necrotising pancreatitis and at the time of antibiotic therapy.

Results-Imipenem accumulates in the pancreas in the initial phase of acute necrotising pancreatitis characterised by pronounced oedema and decreased PCBF, and tends to decrease with resolution of the oedema and the progression of acinar cell necrosis in the later course of the disease. Concentrations of cefotaxime are low in oedematous pancreatic tissue early after induction of acute necrotising pancreatitis and increase with the resolution of oedema and normalisation of PCBF.

Conclusions-Concentrations of antibiotics in the pancreas vary in acute necrotising pancreatitis, depending on changes in pancreatic tissue morphology and capillary blood flow. This suggests that antibiotic tissue concentrations may not be consistent from one agent to another and that efficacy of antibiotics in acute pancreatitis cannot be estimated solely on the basis of their pharmacological and microbiological properties.

(Gut 1997; 40: 526-530)

Keywords: acute pancreatitis, necrosis, capillary blood flow (microcirculation), antibiotic therapy, imipenem, cefotaxime.

Secondary infection of pancreatic necrosis is presently the major cause of morbidity and mortality in acute necrotising pancreatitis. ${ }^{1-3}$ Recent pharmacological and bacteriological studies have identified antibiotics which, unlike previously used drugs, reach bactericidal concentrations in the pancreas and cover those bacteria which usually infect pancreatic necrosis. ${ }^{4}$ Imipenem, one of these antibiotics, has been shown to reduce infectious complications in acute necrotising pancreatitis when started early after the onset of the disease. ${ }^{6}$ Clinical experience has, however, questioned the advantage of imipenem over other antibiotics once the start of antibiotic treatment is delayed - for example, in patients who are admitted several days after the onset of the disease. Furthermore, it has been shown that imipenem concentrations remain inadequate in frank pancreatic necrosis whereas other antibiotics seem to penetrate better into necrotic tissue. ${ }^{7}$ Against this background, we speculated that antibiotic concentrations in pancreatic tissue may vary depending on the evolution of the disease. To test this hypothesis, we measured pancreatic tissue concentrations of imipenem at different stages of acute necrotising pancreatitis (early $v$ late) in an improved animal model which has been shown to mimic closely the morphological and bacteriological features of severe human pancreatitis. ${ }^{89}$ To elucidate whether changes in tissue geometry and regional perfusion occurring in the course of the disease may interfere with the pattern of antibiotic tissue distribution, we determined the amount of necrosis and oedema in the pancreas as well as pancreatic capillary blood flow at the time of antibiotic treatment. Finally, we compared the values obtained for imipenem with those of cefotaxime, another antibiotic widely used in acute pancreatitis. 


\section{Methods}

All experiments were conducted in accordance with the national guidelines for animal care. After an overnight fast, male Sprague-Dawley rats (body weight 310-390 g) were anaesthetised with intraperitoneal pentobarbitone (20 $\mathrm{mg} / \mathrm{kg}$ ) and ketamine $(40 \mathrm{mg} / \mathrm{kg})$. Polyethylene catheters (inner diameter $0.5 \mathrm{~mm}$ ) were inserted into the right jugular vein and the left carotid artery, subcutaneously tunnelled to the neck, and advanced through a steel tether which allowed for blood sampling and intravenous access in the unrestrained animals. As previously described, ${ }^{8}$ acute necrotising pancreatitis was induced by a standardised retrograde infusion of $0.5 \mathrm{ml} 10 \mathrm{mM}$ glycodeoxycholic acid (GDOC; Sigma, St Louis, MO, USA) into the biliopancreatic duct for 10 minutes, followed by a continuous intravenous infusion of $5 \mu \mathrm{g} / \mathrm{kg} / \mathrm{h}$ cerulein (CAE; Farmitalia, Freiburg, Germany) over six hours. At six hours $(n=16)$ and at 48 hours after induction of pancreatitis $(n=16)$, the animals were randomised for an intravenous injection of either $13 \mathrm{mg} / \mathrm{kg}$ imipenem or $33 \mathrm{mg} / \mathrm{kg}$ cefotaxime. Animals without pancreatitis treated with the same doses of imipenem and cefotaxime served as controls. Fifteen minutes after injection of the antibiotic, blood was drawn to determine imipenem and cefotaxime in serum; then the animals were killed by an intra-arterial injection of pentobarbitone $(200 \mathrm{mg} / \mathrm{kg})$. At necropsy, the head of the pancreas was harvested for determination of imipenem and cefotaxime in tissue. All samples were immediately frozen in liquid nitrogen and stored at $-80^{\circ} \mathrm{C}$. The splenic portion of the pancreas was used for histological examination and determination of the wet:dry ratio.

\section{HISTOLOGY}

Pancreatic oedema and acinar cell necrosis were evaluated and scored according to previously described criteria. ${ }^{8}$ The pancreatic water content was determined by calculating the ratio between the initial weight of the specimens (wet weight) and their weight after incubation at $210^{\circ} \mathrm{C}$ for 12 hours (dry weight).

\section{ANTIBIOTIC CONCENTRATIONS IN SERUM AND} TISSUE

After completion of the experiments, blood and pancreatic tissue samples were thawed, vigorously mixed, and centrifuged for five minutes at $3600 \mathrm{rpm}$. To determine imipenem, deproteinisation was carried out by ultrafiltration (Amicon, Micropartitionssystem MPS-1) after adding the internal standard. An aliquot of the filtrate $(180 \mu \mathrm{l})$ was injected into a high performance liquid chromatography (HPLC) system. Quantification of imipenem was based on chromatographic separation on a reversed phase column (Spherisorb ODS II) using a mixture of $0.6 \mathrm{M} \mathrm{NaH} \mathrm{NO}_{4}$ and acetonitrile $(98 \cdot 5 / 1 \cdot 5 ; \mathrm{v} / \mathrm{v})$ as the mobile phase. The $\mathrm{pH}$ was adjusted to 6.55. Detection was achieved with a GAT-LCD 501 detector at $300 \mathrm{~nm}$. The retention times of imipenem and the internal standard were 13 and 18 minutes respectively. Turbochrom software (version 3.2, 1991; PE Nelson, Cupertino, CA, USA) was used for evaluating the chromatograms. To determine cefotaxime, $100 \mu \mathrm{l}$ of the samples were stabilised with sodium acetate buffer $(100 \mu \mathrm{l})$ and deproteinised by addition of $400 \mu$ l acetonitrile containing an internal standard. After mixing and centrifugation at $3600 \mathrm{rpm}$, the acetonitrile was removed by extraction with 1 $\mathrm{ml}$ dichloromethane. After centrifugation at $3600 \mathrm{rpm}$ for five minutes, $120 \mu \mathrm{l}$ of the aqueous phase were injected into the HPLC system. The chromatographic separation was performed on a Spherisorb ODS II, $5 \mu \mathrm{m}$ (125 $\times 4.6 \mathrm{~mm}$ internal diameter) column using an isocratic solvent system consisting of $0.05 \mathrm{M}$ potassium dihydrogen phosphate buffer and acetonitrile containing $5 \mathrm{mM}$ tetrahexyl ammonium chloride $(83 / 17: \mathrm{v} / \mathrm{v})$. The retention times of cefotaxime and the internal standard were eight and 7.5 minutes respectively. The eluent was monitored by UV detection with a wavelength of $254 \mathrm{~nm}$, and Turbochrom software (see above) was used for evaluating the chromatograms. To evaluate regional pancreatic perfusion, the number of perfused capillaries and capillary pancreatic blood flow (PCBF) at the time of antibiotic treatment were determined in another set of identically treated animals by intravital microscopy using the equipment and technique previously described. ${ }^{10}{ }^{11} \mathrm{Six}$ and 48 hours after induction of acute necrotising pancreatitis, animals were reanaesthetised, the pancreas was exteriorised, placed in an immersion chamber with Ringer's lactate maintained at $37^{\circ} \mathrm{C}$, and positioned under a fluorescence microscope (Leitz, Wetzlar, Germany) with a heat protection and an excitation filter (450-490 $\mathrm{nm})$. At that point, the animals received an intravenous injection of $0.5 \mathrm{ml} / \mathrm{kg}$ erythrocytes labelled with fluorescein isothiocyanate (FITC; Sigma, Deisenhofen, Germany). After a stabilisation period of 15 minutes, three randomly chosen regions in the head of the pancreas (325-400 $\mu \mathrm{m})$ were recorded for off line analysis. In each animal, blood flow was calculated in 30-40 consecutively recorded capillaries from the concentration of fluorescent erythrocytes per unit of arterial blood at the time of the recording, the capillary packed cell volume, and the number of FITC labelled erythrocytes passing through the respective vessel. ${ }^{10}$ Capillary stasis was ascribed if there were no labelled erythrocytes passing through the capillary within the recording time (three to five minutes). Measurements in Ringer's lactatepretreated animals without pancreatitis served as additional controls. Cardiorespiratory monitoring included continuous measurements of the mean arterial pressure and heart rate as well as repeated control of the arterial blood gases and comparison of the packed cell volume before and after intravital microscopic examination to ensure stability of the preparation. Because systemic circulatory derangement may influence the distribution and regional concentration of the antibiotic, animals with unstable blood pressure (MAP $<90 \mathrm{~mm} \mathrm{Hg}$ ) were excluded from analysis. 
Concentrations (mean (SEM)) of imipenem and cefotaxime in serum and pancreatic tissue before (0 hrs) and after (six and $48 \mathrm{hrs)}$ induction of pancreatitis

\begin{tabular}{llllll}
\hline & \multicolumn{3}{l}{ Imipenem } & & \multicolumn{2}{l}{ Cefotaxime } \\
\cline { 2 - 3 } \cline { 5 - 6 } $\begin{array}{l}\text { Time } \\
\text { (hr })\end{array}$ & $\begin{array}{l}\text { Serum } \\
(\mu \mathrm{g} / \mathrm{ml})\end{array}$ & $\begin{array}{l}\text { Tissue } \\
(\mu \mathrm{g} / \mathrm{g})\end{array}$ & & $\begin{array}{l}\text { Serum } \\
(\mu \mathrm{g} / \mathrm{ml})\end{array}$ & $\begin{array}{l}\text { Tissue } \\
(\mu \mathrm{g} / \mathrm{g})\end{array}$ \\
\hline 0 & $26(2)$ & $1 \cdot 8(0 \cdot 4)$ & $56(3)$ & $10 \cdot 0(1 \cdot 6)$ \\
6 & $29(2)$ & $13 \cdot 2(0 \cdot 6)^{\star}$ & $47(5)$ & $2 \cdot 1(0 \cdot 4)^{\star}$ \\
48 & $27(2)$ & $10 \cdot 8(0 \cdot 9)^{\star}$ & $50(5)$ & $6 \cdot 8(1 \cdot 3)^{\star \star}$ \\
\hline
\end{tabular}

${ }^{\star} \mathrm{p}<0.05 v 0 \mathrm{hr} ;{ }^{\star \star} \mathrm{p}<0.05 v 6 \mathrm{hr}$.

STATISTICS

All results are expressed as mean (SEM). Variables were tested for group differences with Student's $t$ test. A p value $<0.05$ was considered significant.

\section{Results}

Compared with healthy control animals, pancreatic tissue concentrations of imipenem were significantly increased six hours and 48 hours after induction of acute necrotising pancreatitis. Six hour values tended to be higher than 48 hour values $(p=0 \cdot 054)$. Tissue concentrations of cefotaxime measured in animals six hours after induction of acute necrotising pancreatitis were significantly lower than those of healthy control animals; 48 hours after pancreatitis induction they had significantly increased and did not differ from baseline values. No significant differences were found in serum concentrations of imipenem or cefotaxime at different time points (Table). Likewise, the ratio between the tissue and serum concentrations of imipenem was significantly increased in rats with six and 48 hours of acute necrotising pancreatitis (compared with the ratios determined in healthy control animals), whereas for cefotaxime it was decreased six hours after induction of acute necrotising pancreatitis, and significantly increased after 48 hours, reaching values comparable with those obtained in rats without pancreatitis (Fig 1). Histology showed pronounced interstitial oedema and moderate acinar cell necrosis six hours after induction of acute necrotising pancreatitis; at 48 hours oedema had significantly declined and necrosis had significantly increased (Fig 2). In accordance with the macroscopic and histological findings, the wet:dry weight ratio of pancreatic tissue was increased almost threefold six hours after induction of acute necrotising pancreatitis. With resolution of the oedema, the water

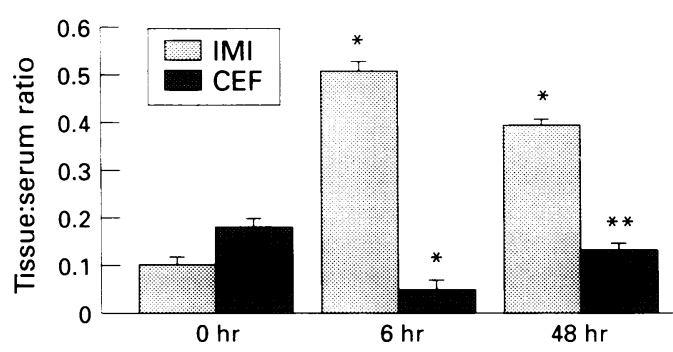

Figure 1: Tissue:serum ratio of imipenem (IMI) and cefotaxime (CEF) before $(0 \mathrm{hr})$ and $6 \mathrm{hr}$ and $48 \mathrm{hr}$ after induction of pancreatitis.

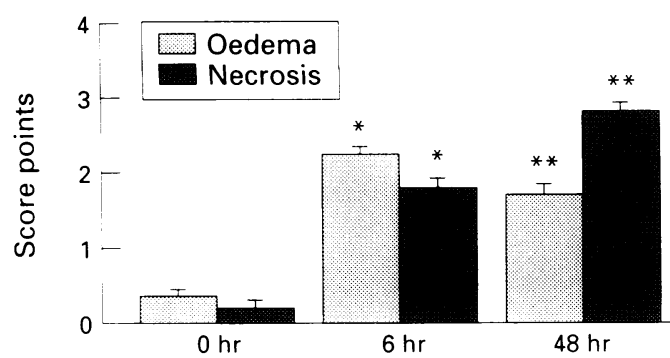

Figure 2: Pancreatic oedema and acinar cell necrosis before $(0 \mathrm{hr})$ and $6 \mathrm{hr}$ and $48 \mathrm{hr}$ after induction of pancreatitis.

content significantly decreased until 48 hours but was still increased compared with normal pancreatic tissue (Fig 3). The PCBF was reduced six hours after induction of acute necrotising pancreatitis and had returned almost to baseline values by 48 hours (Fig 4 ).

\section{Discussion}

CLINICAL BACKGROUND

Recent pharmacological and microbiological studies have suggested that cephalosporines, quinolones, imipenem, and metronidazole are adequate to prevent and treat pancreatic infections, whereas aminoglycosides and ampicillin used in earlier studies did not always reach bactericidal concentrations in the pancreas or cover the bacteria isolated from the infected pancreatic tissue. ${ }^{5}$ 12-14 Subsequent clinical trials confirmed that prophylactic treatment with imipenem or cefuroxime

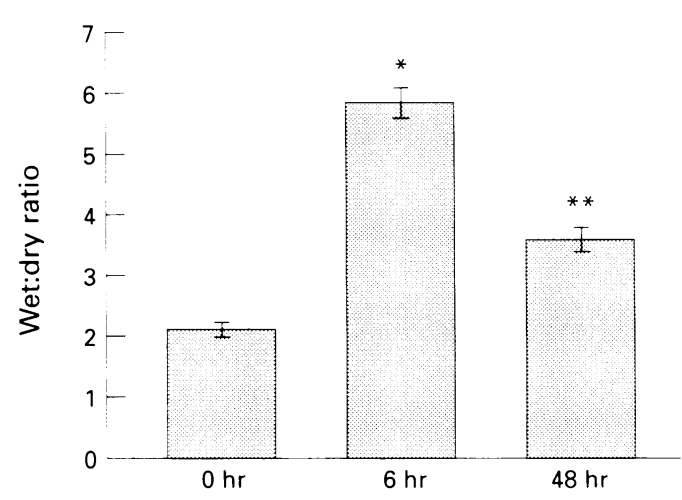

Figure 3: Weight:dry weight ratio of pancreatic tissue before $(0 \mathrm{hr})$ and $6 \mathrm{hr}$ and $48 \mathrm{hr}$ after induction of pancreatitis.

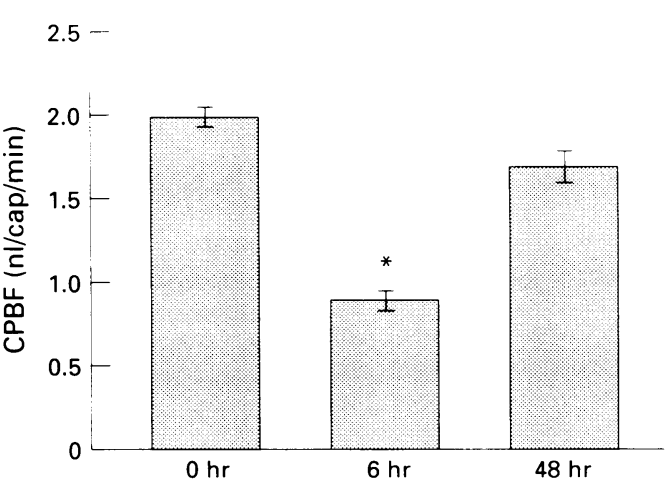

Figure 4: Capillary pancreatic blood flow (CPBF) before $(0 \mathrm{hr})$ and $6 \mathrm{hr}$ and $48 \mathrm{hr}$ after induction of pancreatitis. 
significantly reduced pancreatic infections and septic complications in patients with acute necrotising pancreatitis compared with those who received antibiotics only when infection was clinically apparent. ${ }^{6}{ }^{15}$ Thus it has been recommended that patients with acute necrotising pancreatitis should be prophylactically given antibiotics with appropriate pharmacokinetic properties. The effects of antibiotics in acute necrotising pancreatitis are, however, poorly understood, and the data reported are based on very few samples of patients with various forms of pancreatic diseases. ${ }^{57}$ Therefore, it was the aim of this study to elucidate further factors which may influence antibiotic tissue concentrations in the course of acute pancreatitis - namely, the extent of acinar cell necrosis and pancreatic capillary blood flow.

\section{METHODOLOGICAL ASPECTS}

We have recently developed and characterised an improved model of acute necrotising pancreatitis in the rat which closely mimics the morphological and bacteriological features of severe human pancreatitis. ${ }^{8} 9$ Having shown its suitability for studying both the pathophysiology of bacterial infection of the pancreas in acute necrotising pancreatitis and antimicrobial strategies for the prevention of bacterial contamination of pancreatic tissue, ${ }^{9} 16$ we now used this model to evaluate further the effect of morphological alterations and changes in capillary pancreatic perfusion on antibiotic tissue concentrations. Antibiotics were first given six hours after the start of pancreatitis induction, which represents the early stage of the disease, characterised by pronounced pancreatic oedema, initial acinar cell necrosis, and microcirculatory derangement. The second time point for measurements was chosen at 48 hours after induction when pancreatic necrosis was fully developed. Because it has been shown that pharmacological characteristics of the antibiotic (for example, molecular weight, structure, polarity, $\mathrm{pK}$, ionisation, lipid solubility) affect their ability to penetrate and accumulate in tissue, ${ }^{17-20}$ we compared tissue concentrations of two different drugs (imipenem and cefotaxime,) which are both pharmacologically well characterised and widely used for antibiotic treatment in acute necrotising pancreatitis..$^{5-7}$ 21-27 Doses of antibiotics used in the current experiments were adopted from previous studies in small rodents and this model of acute necrotising pancreatitis, ${ }^{9}$ and additional pilot studies had been performed to assure that the 15 minute period between the injection of the drug and tissue collection was sufficient for the antibiotics to penetrate into the pancreas. Determination of the serum and tissue concentrations of the antibiotics were performed by established methods - namely, chromatographic separation. The concentrations in the pancreas were measured in tissue homogenates, which does not allow for conclusions on the distribution of the drug within the different tissue compartments. Because of the high vulnerability of the pancreas, it was not possible to retrieve extracellular pancreatic tissue fluid - for examle, by a thread implanted into the pancreas at the time of pancreatitis induction or by soaking fluid on to paper discs after removal of the capsule at the time of necropsy - as can be performed in healthy muscle. ${ }^{25}$ Therefore, we measured the antibiotic tissue concentration in one portion of the pancreatic specimen and determined the wet:dry weight ratio and the degree and extent of oedema and acinar cell necrosis in the other half. This seemed to be a reasonable approach as the model is characterised by uniform morphological changes throughout the entire pancreas. ${ }^{8}$

\section{INTERPRETATION OF RESULTS}

Serum concentrations of imipenem and cefotaxime measured in healthy rats and animals with acute necrotising pancreatitis six and 48 hours after induction did not significantly differ. Imipenem concentrations in the inflamed pancreas exceeded those in normal pancreatic tissue. This has also been found by other investigators. ${ }^{7}$ It may in part be due to the nature of the pancreas as an excretory organ and the use of cerulein for pancreatitis induction, which is highly stimulatory to the exocrine pancreas. After 48 hours, imipenem tissue concentrations were notably lower than after six hours (although not significant; $p=0.054$ ) but still higher than the minimum inhibitory concentrations for the organisms usually isolated from infected pancreatic tissue in this model of acute necrotising pancreatitis in the rat as well as in severe human pancreatitis. ${ }^{7}$ Antibiotic tissue concentrations seemed to correlate with the degree of oedema, which may suggest that imipenem accumulated in the relatively small volume of interstitial fluid. This is in accordance with data on the rat granuloma pouch, which shows high concentrations of imipenem in the inflammatory exudate and at the site of local inflammation (principally oedema). ${ }^{22}{ }^{23}$ It also corresponds with the measurements in resected pancreatic tissue in human acute necrotising pancreatitis, where there is an accumulation of imipenem, especially in perinecrotic (oedematous) tissue. ${ }^{7}$ Decreasing concentrations of imipenem with resolution of oedema and manifestation of necrosis on the other hand parallel these findings and suggest that imipenem, which has a good water solubility and moderate liposolubility, may not freely penetrate into the acinar cells. Again, this is in accordance with the findings of Bassi et $a l^{7}$ that imipenem did not always reach sufficient concentrations in necrotic pancreatic tissue. Accumulation in the interstitial space early in acute necrotising pancreatitis (when the pancreas is not yet infected) may, however, be an advantage rather than a disadvantage because the bacteria are thought to arrive in the pancreas through the same route, penetrating from the extracellular space into the cells. ${ }^{17} 18$ Another advantage of imipenem is that it reaches high pancreatic tissue concentrations despite significantly decreased pancreatic capillary blood flow. Experiments in 
which we increased PCBF by isovolaemic haemodilution with dextran failed to improve significantly the tissue concentration of imipenem, suggesting the accumulation of this specific antibiotic in the pancreas does not depend on an intact regional perfusion..$^{28} \mathrm{By}$ contrast, pancreatic tissue concentrations of cefotaxime remained inadequately low early in acute necrotising pancreatitis and only reached minimum inhibitory concentrations after 48 hours when oedema had decreased and PCBF had returned to almost normal values. Low pancreatic tissue concentrations (in the presence of high serum concentrations) would explain our previous finding that cefotaxime did not prevent early pancreatic infection (but protected the kidney). ${ }^{16}$ Corresponding values of PCBF and cefotaxime tissue concentrations found in healthy rats and animals with acute necrotising pancreatitis at 48 hours, despite significant morphological differences, suggest that cefotaxime, unlike imipenem, demands sufficient regional perfusion to reach the pancreas in adequate concentrations. This hypothesis was underlined by experiments showing that tissue concentrations of cefotaxime could be improved by enhancement of PCBF (data not published). The dissimilar impact of pancreatic microcirculation on the tissue concentration of imipenem and cefotaxime would also explain why those differences were more striking in our experiment than in the study of Büchler et $a l^{5}$ in which measurements were performed in a heterogeneous group of patients with pancreatic neoplasm, chronic and acute pancreatitis (at a later stage) in which pancreatic perfusion is not compromised as much as in early severe acute pancreatitis. Although the experimental design did not permit firm conclusions on the pathway by which the antibiotics reached the necrotic foci, our results clearly indicate (1) that changes in PCBF and morphology occurring in the course of acute necrotising pancreatitis influence the antibiotic tissue concentrations and (2) that tissue concentrations may not be consistent at any given time point and from one antibiotic to another. Therefore, efficacy of antibiotic treatment in acute pancreatitis cannot be estimated solely on the basis of in vitro pharmacological and microbiological studies, but requires evaluation in vivo. More work in this field is necessary to optimise antibiotic therapy, which presently is the best tool for futher improving the outcome of this life threatening disease. Preferably, these studies should be performed as controlled clinical trials. As setting up clinical studies is, however, limited in acute necrotising pancreatitis due to the paucity of severe cases in any one institution, the great variability in the clinical course of the disease, and the invasiveness of procedures for obtaining pancreatic specimens, further animal studies are required. The present study shows that data obtained from these types of experiments can provide information of clinical relevance provided that the animal model and the study design closely mimic the features and the course of severe human pancreatitis.
This work was presented in part at the Annual Meeting of the American Pancreatic Association, Chicago, November 1995.

1 Beger HG, Block S, Bittner R. The significance of bacterial infection in acute pancreatitis. In: Beger HG, Büchler M eds. Acute pancreatitis. Berlin: Springer, 1987: 79-86.

2 Bradley EL. Overview. In: Bradley EL, ed. Complications of pancreatitis. Philadelphia: WB Saunders, 1982: 1-15.

3 Widdison AL, Karanja ND. Pancreatic infection complicating acute pancreatitis [review]. Br $\mathcal{F}$ Surg 1993; 80: 148-54.

4 Beger HG, Bittner R, Block S, Büchler M. Bacterial contamination of pancreatic necrosis. Gastroenterology 1986; 91: 433-8.

5 Büchler M, Malfertheiner P, Friess H, Isenmann R, Vanek E, Grimm $\mathrm{H}$, et al. Human pancreatic tissue concentration of bactericidal antibiotics. Gastroenterology 1992; 103: 1902-8.

6 Pederzoli P, Bassi C, Vesentini S, Campedelli A, Pederozoli P. A randomized multicenter clinical trial of antibiotic prophylaxis of septic complications in acute necrotizing pancreatitis with imipenem. Surgical Gynecology and Obstetrics 1993; 176: 480-3.

7 Bassi C, Pederzoli P, Vesentini S, Falconi M, Bonora A, Abbas $\mathrm{H}$, et al. Behaviour of antibiotics during human necrotizing pancreatitis. Antimicrob Agents Chemother 1994; 38: 830-6.

8 Schmidt J, Rattner DW, Lewandrowski K, Compton CC, Mandavilli U, Knoefel WT, Warshaw AL. A better model of acute pancreatitis for evaluating therapy. Ann Surg 1992; 215: 44-56.

9 Foitzik T, Mithöfer K, Ferraro MJ, Fernandez-del Castillo C, Lewandrowski KB, Rattner DW, Warshaw AL. The time course of bacterial infection of the pancreas and its relation to disease severity in a rodent model of acute necrotizing pancreatitis. Ann Surg 1994; 229: 193-8.

10 Mithöfer K, Schmidt J, Gebhard MM, Buhr HJ, Herfarth C, Klar E. Measurement of blood flow in pancreatic exchange capillaries with FITC-labelled erythrocytes. Microvas Res 1995; 49: 33-48.

11 Hotz HG, Schmidt J, Ryschich EW, Foitzik T, Buhr HJ, Warshaw AL, et al. Isovolemic hemodilution with dextran prevents contrast medium induced impairment of panprevents contrast medium induced impairment of pancreatic microcirculation in necro
rat. $A m \mathcal{F}$ Surg 1995; 169: 161-6.

12 Finch WT, Sawyers JL, Schenker S. A prospective study to determine the efficacy of antibiotics in acute pancreatitis. Ann Surg 1976; 183: 667-71.

13 Howes R, Zuidema GD, Cameron JL. Evaluation of prophylactic antibiotics in acute pancreatitis. $\mathcal{F}$ Surg Res 1975; 18: 197-200.

14 Craig RM, Dordel E, Myles L. The use of ampicillin in acute pancreatitis. Ann Intern Med 1975; 83: 831-2.

15 Saino V, Kemppainen E, Puolakkainen P, Taavitsainen M, Kivisaari L, Haapiainen $\mathrm{R}$, et al. Early antibiotic treatment in acute necrotising pancreatitis. Lancet 1995; 346: 663-7.

16 FoitzikT,Fernandez-del Castillo C, Ferraro MJ, RattnerDW, Warshaw AL. Pathogenesis and prevention of early pancreatic infection in experimental acute necrotizing pancreatitis. Ann Surg 1995; 222: 179-85.

17 Bergan T. Pharmacokinetics of tissue penetration of antibiotics. Rev Infect Dis 1981; 3: 45-66.

18 Barza M. Principles of tissue penetration of antibiotics. $f$ Antimicrob Chemother 1981; 8 (suppl C): 7-28.

9 Ryan DM, Cars O, Hoffstedt B. The use of antibiotic serum levels to predict concentrations in tissues. Scand $\mathcal{F}$ Infect Dis 1986; 18: 381-8.

20 Adam $D$. Tissue concentrations of cephalosporine antibiotics in man. In: Van der Waaij D, Verhoef J, eds. New criteria for antimicrobial therapy. Amsterdam: Excerpta Medica, 1979: 174-83.

21 Papenburg R, Vallee F, LeBel M, Brown R, Fleiszer D. Tissue penetration of cefotaxime in normal pigs and pigs with hemorrhagic pancreatitis $\mathcal{F}$ Antimicrob Chemother 1990; 26 (suppl A): 11-4

22 Hashizume T, Okumoto Y, Ogashiwa M, Shimano K. Penetration of imipenem and other antibiotics into inflammatory exudate and their efficacy in pseudomonas infection in the rat granuloma pouch model. $\mathcal{F}$ Antimicrob Chemother 1987; 20: 413-6.

23 Brauer E, Gorbach S, Davey P. Comparative study of clindamycin, imipenem, oxacillin and vancomycin in the infected granuloma pouch model. If Antimicrob Chemother 1989; 23: 891-8.

24 Lankisch PG, Klesel N, Seeger K, Siedel G, Winckler K. Penetration of cefotaxime into the pancreas. $Z$ Gastroenterol 1983; 21: 601-3.

25 Ryan DM, Cars O. A problem in the interpretation of betalactam antibiotic levels in tissues. $\mathcal{F}$ Antimicrob Chemother 1983, 12: 281-4.

26 Van Etta LL, Fasching CE, Peterson LR, Gerding DN. Comparison study of the kinetics of ceftizoxime penetration into extravascular spaces with known surface area/ tration into extravascular spaces with known surface area
volume ratio in vitro and in vivo in rabbits. Antmicrob volume ratio in vitro and in vivo
Agents Chemother 1983; 23: 49-53.

27 Walstad RA, Hellum KB, Blika S, Dale LG, Fredriksen T, Myhre KI, Spencer GR. Pharmacokinteics and tissue penetration of ceftazidime. $\mathcal{f}$ Antimicrob Chemother 1983; 12 (suppl A): 275-82.

28 Foitzik T, Hotz HG, Kinzig M, Sörgel F, KlarE, Warshaw AL, Buhr HJ. Improvement of pancreatic capillary blood flow does not augment the pancreatic tissue concentration of imipenem in acute experimental pancreatitis. Eur $\mathcal{f}$ Surg 1996; 28: 395-401. 